\title{
Colony site characteristics of sympatric breeding tern species on the Mond Islands, the Persian Gulf
}

\begin{abstract}
We have investigated characteristics of colony site of three sympatric breeding tern species on small islands of a subtropical region, the Persian Gulf. The three most populous groundnesting waterbird species - Bridled Tern Onychoprion anaethetus, Lesser Thalasseus bengalensis and Greater Thalasseus bergii Crested Terns - were studied during the 20092011 breeding seasons. The average area size of mixed colonies was $454 \mathrm{~m} 2$. The density of nests of the Bridled Tern was 846 nests/ha. The proportion of the number of nests in a mixed colony for Lesser Crested Tern (5546 nests) was approximately 10-fold compared to the Greater Crested Tern (542 nests). The density of Bridled Tern nests/ha was significantly higher in areas with $50-75 \%$ vegetation cover $(>1200$ nests/ha) than in areas of $<5 \%$ vegetation cover $(72-105$ nests/ha) $(\mathrm{p}<0.05)$. Mixed colonies of the Lesser and Greater Crested Terns were located on unvegetated land, at an average distance of $4.1 \mathrm{~m}$ to vegetation, and on sandy soil ( $79.4 \%$ on average) and above high spring tide water lines $(0.59$ $\mathrm{m}$ on average). There were more potential nesting areas than occupied areas for the mixed colonies of the Lesser and Greater Crested Terns, indicated that they did not face nest site limitation.
\end{abstract}

Keyword: Colony site; Island; Persian Gulf; Waterbird; Tern 